\title{
Phaeochromocytoma of the urinary bladder with acute oliguric renal failure: the use of a plasma catecholamine assay in diagnosis
}

\author{
M. J. CogGIN \\ M.B., M.R.C.P. \\ Lecturer in Nephrology \\ Institute of Urology
}

\author{
A. R. AdAmSON \\ M.A., M.R.C.P. \\ Consultant Physician \\ North Lancashire and South Westmorland \\ Group of Hospitals
}

\author{
J. FINBERG \\ B.Pharm., Ph.D. \\ Medical Unit, St Mary's Hospital \\ London, W.C.2
}

\author{
A. M. JOEKeS \\ M.A., F.R.C.P. \\ Consultant Physician \\ St Peter's Group of Hospitals
}

\section{Introduction}

The diagnosis of phaeochromocytoma is usually made on the clinical presentation and confirmed by the estimation of noradrenaline and adrenaline, or their breakdown products, in the urine. In the presence of oliguria these tests are not possible. A patient is described who became anuric postoperatively and in whom the diagnosis of phaeochromocytoma was assisted by a plasma assay of noradrenaline.

\section{Case history}

R.D. was a girl of 14 , who was admitted to hospital with a history of back pain followed by central abdominal pain.

On admission, she had a temperature of $100^{\circ} \mathrm{F}$, pulse 120 , blood pressure $190 / 80-120$. At various sequential observations, she had right iliac fossa guarding and a diagnosis of acute appendicitis was made.

Laparotomy: under halothane and nitrous oxide anaesthesia, the appendix was normal but the large bowel abnormally distended with faecal contents. The pelvic organs appeared to be matted together and because of the suspicion of genital tuberculosis a dilatation and currettage was carried out.

Postoperatively, tachycardia persisted, her blood pressure was $180 / 120 \mathrm{~mm} \mathrm{Hg}$ and she had a temperature of $104^{\circ} \mathrm{F}$. Within $20 \mathrm{hr}$ of operation her blood pressure dropped to $100 / 80$ and she became photophobic and drowsy. Five hr later her blood pressure became unrecordable, her pulse 140 and she had papilloedema and haemorrhages in her optic fundi.

She was transferred to a renal intensive care unit.
Additional historical points were noted. Earlier in the year, her parents remembered that she had had very severe headache, which had woken her from sleep and she had also had polyurea.

On examination on transfer, she was jaundiged, unconscious and oedematous. Her pupils almost fully dilated, but equal and unreactivêㄴ light. Her gaze was divergent. She had gross papit loedema with retinal haemorrhages and exudate? The limbs were flaccid and areflexic and the plantof responses were equivocal, pulse 110 , blood pressure $140 / 100 \mathrm{~mm} \mathrm{Hg}$ and she had normal femoral pulsa tions. There was a harsh Grade 3 mid-systolic murmur, heard best in the pulmonary area. The liver was enlarged 1 in. below the right costa margin, with a smooth firm edge. The whole colog could be palpated, because of its marked distension with faecal contents. Respiration was sighing and there were signs of pulmonary oedema.

A chest X-ray showed cardiac enlargement and the ECG showed a prominent $P$ wave and the signs of left ventricular hypertrophy. The urine contained no sugar and there were red blood cells present. A radioactive renogram showed bilater nonfunction.

Because of generalized fluid overload with cero bral oedema, an arteriovenous shunt was inserte and she was haemodialysed for $4 \mathrm{hr}$ on a twin colf artificial kidney. Two hours after the start of dialysis her respiratory rate decreased and she stoppef breathing. During intubation, she had a shorw cardiac arrest. She was put on a ventilator.

Following dialysis the blood pressure had remained elevated with diastolic pressures of $110 \mathrm{t} \Phi$ $120 \mathrm{~mm} \mathrm{Hg}$. The whole initial presentation witf 
R.D. 2.3.69.

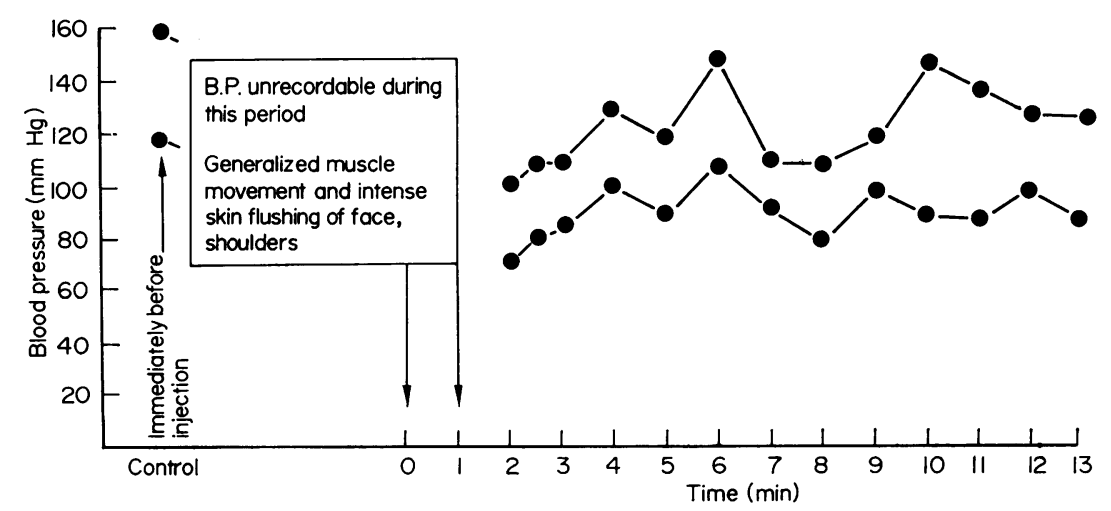

FIG. 1. The graph shows the fall of blood pressure from $160 / 120$ to unrecordable levels after the injection of $4 \mathrm{mg}$ of phentolamine.

abdominal pain, severe hypertension, retinopathy and fever was acceptable as due to malignant hypertension. The pelvic findings and the grossly dilated colon could not be explained on this basis alone but led to the suspicion of a phaeochromocytoma. A phentolamine test was strongly positive (Fig. 1) with a fall of blood pressure to unrecordable levels for $2 \mathrm{~min}$ following a $4 \mathrm{mg}$ intravenous injection. The blood pressure remained below the resting level for $5 \mathrm{~min}$. Parenteral phenoxybenzamine was commenced but this produced hypotension and was discontinued. As urine volumes amounted to a few millilitres in $24 \mathrm{hr}$, a plasma assay was performed (Fig. 2). (For method see below.) This test confirmed the diagnosis, showing a pressor activity equivalent to about $100 \mathrm{ng}$ of noradrenaline per millilitre of plasma.

Unfortunately, the possibility of operative removal of a tumour could not be considered. There was no recovery of spontaneous respiration or consciousness and the patient died after a further cardiac arrest.

Necropsy showed a swollen softened brain. The pericardium was bruised on its anterior surface and the left ventricle was markedly hypertrophied. The colon contained hard faeces. The liver was enlarged and firm. The kidneys were slightly swollen. There was a firm tumour on the anterior wall of the bladder. It was yellowish brown and on cutting it had a circumferential haemorrhage. Histologically, it had the features of a paraganglioma.

\section{Catecholamine assay}

Method. An arterial blood sample $(5 \mathrm{ml})$ was taken and $0.5 \mathrm{mg}$ ascorbic acid added. To another sample was also added $10 \mathrm{ng}$ noradrenaline acid tartrate. The samples were kept on ice and taken
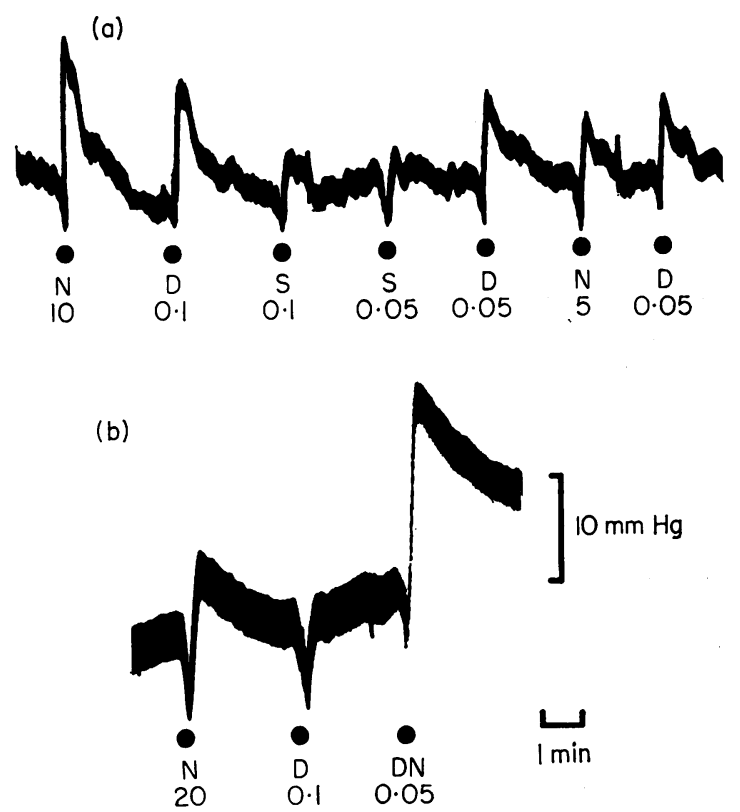

Fig. 2. (a) Blood pressure responses of anaesthetized rat to noradrenaline (N), 10 and $5 \mathrm{ng}$; test plasma (D), $0 \cdot 1$ and $0.05 \mathrm{ml}$; isotonic saline (S), 0.1 and $0.05 \mathrm{ml}$. (b) The same following administration of $10 \mathrm{mg}$ phentolamine $+0.5 \mathrm{mg}$ ergotamine tartrate, which caused a rise of blood pressure of $75 \mathrm{~mm} \mathrm{Hg}$. Responses to $20 \mathrm{ng}$ noradrenaline (N), $0.1 \mathrm{ml}$ test plasma (D), and 0.05 $\mathrm{ml}$ test plasma containing $2 \mathrm{ug} / \mathrm{ml}$ noradrenaline (DN).

immediately to St Mary's Hospital where they were assayed for pressor activity in the anaesthetized, ganglion-blocked rat, against a noradrenaline standard.

Results. The sample with added noradrenaline was found to contain in the region of $1.9 \mathrm{ng} / \mathrm{ml}$ 
noradrenaline showing that a large scale destruction of noradrenaline had been prevented by this treatment.

The patient's plasma contained significant pressor activity in $0.05 \mathrm{ml}$, equivalent to slightly more than $5 \mathrm{ng}$ noradrenaline (Fig. 2a). The pressor response was completely inhibited by treatment with alphaadrenergic blocking agents, which reduced but did not abolish the responses to larger doses of noradrenaline (Fig. 2b).

Thus the pressor agent in plasma appeared similar to noradrenaline, but could not positively be identified as such.

\section{Discussion}

The presenting features of phaeochromocytoma are well known. Oliver (1968) lists these as paroxysmal hypertension with vasomotor features, persistent hypertension in the benign or malignant phase, hypotension, symptoms suggestive of hyperthyroidism, hyperglycaemia and unexpected reactions to investigations and anaesthesia. There is some familial incidence and significant association with thyroid carcinoma and this has been put forward with the presence of ganglioneuromas to suggest a neural crest origin and a hereditary basis (Schimcke et al., 1968). Not surprisingly pregnancy may disclose the presence of a phaeochromocytoma. In the case history described, the only symptoms suggestive of a phaeochromocytoma were fever, tachycardia and abdominal pain, but the single episode of severe headache and the presence of polyuria must lead one to suspect the diagnosis. The relative amounts of adrenaline and noradrenaline secreted by these tumours varies markedly and the symptom pattern depends on this. The most prominent abdominal sign in this patient was the presence of a grossly distended colon. A megacolon has been described in patients with phaeochromocytoma usually in those patients with a coexistent thyroid carcinoma (Schimke et al., 1968). Histological examination has shown the enlargement of ganglion cells in Auerbach's and myenteric plexuses.

On presentation to hospital, our patient was hypertensive and following operation she was still noted to have a raised blood pressure which subsequently fell below normal. During anaesthesia and surgery there was presumably a great release of catecholamines from the tumour, with a great increase in the blood pressure. The dangers during anaesthesia when the diagnosis is not suspected are greater in short operations when the methods of monitoring are less rigidly applied (Seward, 1961). One of the most critical times is during the induction phase, with periods of anoxia. If the diagnosis is not suspected then it is possible that an unsuitable anaesthetic might be chosen. Cyclopropane and tri- chloroethylene stimulate catecholamine release fron normal stores and from the tumour and sensitize the myocardium to their effects (Ross et al., 1967)? Thiopentone reduces the blood pressure, especially: in patients who have had preoperative alpha and beta blockade. Halothane, in the presence of raised $\mathrm{PaCO}_{2}$, also stimulates catecholamine release (Black et al., 1959). It is a common finding tha $\mathrm{PaCO}_{2}$ levels are raised by halothane, when this anaesthetic agent is being breathed spontaneously.

Hypertension in phaeochromocytoma is explicable on a number of bases. In the patient we have des? cribed, it is possible that the catecholoamine release may have ceased and the hypotensive phase whicle occurred might best be compared with that which is known to occur following the cessation of a large infusion of noradrenaline in the dog (Leveris Mowbray \& Peart, 1961) or of adrenaline in man (Green et al., 1948; Koehler, Marsh \& Hill, 1937)市 Lever et al. (1961) produced evidence that the hypois tension which follows cessation of a noradrenaline infusion might be due to release of a vasodilatof substance. The infusion of a high dose of noradrenaline in dogs was followed by a period of hypotension associated with a reduced cardiae. output (Langford, 1960). Hypotension has also beento attributed to arrhythmias, alone (Durant \& Sole्gf, 1962) or in association with myocardial damage (Northfield, 1967). The hypotensive phase may associated with cardiac, peripheral or centra nervous mechanisms depending on the conditions and the species. Hypotension followed hypertensive attacks in a patient, from an adrenaline-secreting tumour (Richmond, Frazer \& Millar, 1961). Since. our patient's tumour was in the bladder, it was probably a noradrenaline-secretor (Albores-Soavedra et al., 1969). It was probably as a consequence of the hypotension that renal failure developed (Carpente? and Kunin, 1951).

Following administration of large volumes of fluid the patient's blood pressure was returned tón normal. Waldmann (1966) reports the correction of hypotension, after the removal of a phaeochromo 0 cytoma, by the administration of a volume of fluide considerably greater than the calculated deficito Waldmann also found that the red cell mass and albumin space were generally within normal limitso in patients with phaeochromocytoma. A reduced intravascular volume is therefore unlikely ton account for the hypotension. The fluid overload may serve to counteract a peripheral vasodilatation.

By the time that the patient had been transferred to the renal unit hypertension had returned and it was decided to perform the phentolamine test although it was appreciated that this would be difficult to interpret being subject to false positive and negative results (Sheps et al., 1960) as well as 
being a potentially dangerous procedure (Pickering, 1968). Emlet et al. (1951) found falls in blood pressure in patients with hypertension and uraemia, but without phaeochromocytoma. However the positive test was associated with an elevated catecholamine concentration on bio-assay.

It was the critical state of the patient and the urgency of the situation which caused the search for a raised level of catecholamine by bio-assay to be made. In the presence of anuria, there is no possibility of carrying out most of the tests usually performed in making the diagnosis and many of the biochemical plasma investigations are interfered with by the presence of abnormal substances, lack of sensitivity (Seref Zileli et al., 1958) or rapidity. Peripheral venous blood from a patient phaeochromocytoma does not normally contain enough catecholamine to be detected in the type of assay which was performed. The high level found here may represent the effect of elevated secretion rate combined with the absence of urinary elimination. Catecholamine levels in the blood are also known to be elevated following histamine stimulation (Bollman et al., 1960), during hypertensive attacks due to phaeochromocytoma (Sheps et al., 1966) and in acutely ill patients (Gitlow et al., 1961). The levels are reduced after a hypertensive episode (Lund, 1952). It is possible that a large release of catecholamine occurred at the time blood was collected for the test, but hypertension was not provoked because of an unreactive cardiovascular system. It is equally possible that the catecholamine secretion was continuously high after operation, and the eventual hypotension was the result of myocardial or cerebral damage. The activity detected in the plasma of this patient could possibly be attributed to diminished excretion or hypotension resulting in catecholamine secretion, or the release of other pressor substances. However in the plasma samples of two other patients, one hypotensive after a crush injury and the other anephric and following haemodialysis, no significant pressor activity could be detected.

Pugh, Gresham \& Mullaney, in 1960 reported on six cases of bladder phaeochromocytoma, some of their own and some from the reports of others. At that time, it seemed to be an exclusively female disease. Albores-Soavedra et al. (1969), discussing the twenty-four published cases found that the female to male ratio was 1.6 to 1 . Cases presented mostly in the fourth and less commonly in the second decade. They presented with painless haematuria, frequency, nocturia and tenesmus. More than half had symptoms that could be related to catecholamines (headache, sweating and paroxysmal or sustained hypertension). These symptoms may occur on micturition or cystography. In the case described above the only historical points before her admission to hospital were polyuria and an isolated severe headache and so without the operative findings the site of the tumour would not have been suspected.

It is the purpose of this report to outline some of the lesser known features in the presentation of phaeochromocytoma and under the difficult circumstances of oliguric renal failure to suggest a simple and speedy way of determining the presence of pressor activity in the plasma.

\section{Acknowledgments}

We wish to thank Mr David W. Bain, F.R.C.s., for kindly referring this patient, Prefessor Francis Camps for his help with the pathology and also to thank the photographic and medical illustration departments of St Mary's Hospital and the Institute of Urology for their work in the production of the chart and tracings for publication.

\section{References}

Albores-Soavedra, J., Maldonado, M.E., Ibarra, J. \& Rodriguez, H.A. (1969) Pheochromocytoma of the urinary bladder. Cancer, 23, 1110.

Black, G.W., Linde, H.W., DripPS, R.D. \& Price, H.L. (1959) Circulatory changes accompanying respiratory acidosis during halothane (fluothan) anaesthesia in man. British Journal of Anaesthetics, 31, 238.

Bollman, J.L., Flock, E.V., Roth, G.M. \& Kvale, W.F. (1960) Catecholamines in patients with pheochromocytoma. Journal of Laboratory and Clinical Medicine, 56, 506.

Carpenter, A.A. and Kunin, A.S. (1951) Phaeochromocytoma with acute tubular necrosis. New England Journal of Medicine, 265, 986.

Durant, J. \& Soloff, L.A. (1962) Arrhythmic crisis of phaeochromocytoma. Lancet, ii, 124.

Emlet, J.R., Grimson, K.S., Bell, D.M. \& Orgain, E.S. (1951) Use of piperoxan and regitine as routine tests in patients with hypertension. Journal of the American Medical Association, 146, 1383.

Gitlow, S.E., Mendlowitz, M., KRUK, E. \& Khassis, S. (1961) Diagnosis of pheochromocytoma by assay of catecholamine metabolites. Circulation Research, 9, 746.

Green, D.M., Johnson, A.D., LubB, A. \& Cusick, G. (1948) Effects of adrenaline on normal and hypertensive patients in relation to the mechanism of sustained pressure elevation. Journal of Laboratory and Clinical Medicine, 33, 332.

Koehler, A.E., Marsh, N. \& Hill, E. (1937) Effect of epinephrine injected intravenously at a constant rate in normal and hypertensive cases. Journal of Biological Chemistry, 119, 59.

LANGFORD, H.G. (1960) Hemodynamic consequences of reinin tachyphylaxis and norepinephrine failure of response. American Journal of Physiology, 198, 561.

LeVer, A.F., Mowbray, J.F. \& PearT, W.S. (1961) Blood flow and blood pressure after noradrenaline infusions. Clinical Science, 21, 69.

LUND, A. (1952) Adrenaline and noradrenaline in blood and urine in cases of pheochromocytoma. Scandinavian Journal of Clinical and Laboratory Investigation, 4, 263.

NorTHFiELD, T.C. (1967) Cardiac complications of phaeochromocytoma. British Heart Journal, 29, 588.

OLIVER, D.O. (1968) The diagnosis and management of phaeochromocytoma. Hospital Medicine, 2, 1279. 
Pickering, Sir G.W. High blood pressure, 2nd edn, p. 545. J. \& A. Churchill, London.

Pugh, R.C.B., Gresham, G.A. \& Mullaney, J. (1960) Phaeochromocytoma of the urinary bladder. Journal of Pathology and Bacteriology, 79, 89.

Richmond, J., Frazer, S.C. \& Millar, D.R. (1961) Paxoxysmal hypotension due to an adrenaline-secreting phaeochromocytoma. Lancet, ii, 904.

Ross, E.J., Prichard, B.N.C., Kaufman, L., Robertson, A.I.G. \& HARRIES, B.J. (1967) Preoperative and operative management of patients with phaeochromocytoma. British Medical Journal, i, 191.

Schimke, R.N., Hartmann, W.H., Prout, T.E. \& Rimoin, D.L. (1968) Phaeochromocytoma, medullary thyroid carcinoma and multiple neuroma. New England Journal of Medicine, 279, 1.

Seref Zileli, M., Hamlin, J.T. III, Reutter, F.W. \&市 FRIEND, D.G. (1958) Evaluation of catechol amine levels ${ }_{C}$ in renal insufficiency. Journal of Clinical Investigations, 37, 409.

SEWARD, E.H. (1961) Death from phaeochromocytoma? Lancet, ii, 903.

ShePs, S.G., Tyce, G.M., Flock, E.V. \& MAHER, F.T.흐 (1966) Current experience in the diagnosis of pheochromo- $\overline{-}-\bar{T}$ cytoma. Circulation, 34, 473.

WALDMANN, T.A. (1966) Circulating blood volume in patients with phaeochromocytoma. Annals of Internal Medicine, 65, 1308.

\section{Multiple adenomatosis presenting with psychiatric manifestations}

\author{
M. W. P. CARNEY* \\ M.D., M.R.C.P.I., D.P.M. \\ Consultant Psychiatrist \\ Blackpool and Fylde Hospital Group and \\ Lancaster Moor Hospital \\ F. JACKSON \\ M.B., Ch.B. \\ General Practitioner \\ Kirkham
}

Though hyperinsulinism is a common manifestation of multiple adenomatosis and the association between hypoglycaemia and mental disturbance is well recognized, only one instance of multiple adenomatosis presenting as an acute psychosisdepression - has been reported (Fullerton, Lohrenz \& Holrey, 1967). There is no record of an association with mental retardation.

For this reason we present a case of multiple adenomatosis presenting with confusional episodes and violent behaviour in a mentally retarded patient.

\section{Case Report}

The patient, a 27-year-old warehouseman, was referred (March 1967) as a psychiatric emergency because of several bouts of aggressive and destructive behaviour. He was disorientated and behaved inappropriately in the attacks, and also sweated and showed a violent tremor. There were no convulsions. He had no subsequent recollection of the attacks.

History. He had always been backward. Nine

\footnotetext{
* Present address: 382 Clifton Drive North, St Annes on Sea, Lancashire, England.
}

\author{
I. WEINBREN \\ M.A., M.B., M.R.C.P.(Lond.) \\ Consultant Physician \\ Blackpool and Fylde Hospital Group \\ G. V. Purnell \\ M.B., Ch.B. \\ General Practitioner \\ Kirkham
}

years previously, when examined after a head injury with transient unconsciousness, he had shown un- $\overrightarrow{\vec{O}}$ steadiness, tremor, difficulty in reading, writing, $\exists$ calculating and memorizing (only three digits for-? wards and backwards) - signs not attributed to head? injury but linked with his subnormality-ando pes cavus.

Family History. His father had suffered from similar bouts of violent behaviour, particularly if (according to his mother) the evening meal was late. He had died following operation and necropsy had shown an 'islet cell secreting tumour of the pancreas and calcification of the kidneys'. No record of the condition of the parathyroid glands was made.

On examination, he was orientated and co-opera- $N$ tive, but slow in grasp. Blood pressure was 130/80.

Investigation. Hourly blood sugars were taken during a prolonged fast. At $16 \mathrm{hr}$ he became violent $\mathrm{\omega}$ and the blood sugar was found to be $20 \mathrm{mg} / 100 \mathrm{ml}$. Glucose immediately restored the level to normak and the violent behaviour ceased. Electro-encephalo- $\mathbb{D}$ graphy showed on hyperventilation a paroxysm of ${ }^{-}$ slow activity, maximal on the left side.

Serum insulin was measured by the radio immuno $\frac{\vec{D}}{\mathrm{D}}$ assay method (Dr Vincent Marks). The fasting 